\title{
Akurasi Pemeriksaan Auskultasi Jantung dan Elektrokardiografi untuk Deteksi Kelainan Jantung pada Anak
}

\author{
Ria Nova, ${ }^{1}$ Deny Salverra Yosy, ${ }^{1}$ Bermansyah ${ }^{2}$ \\ ${ }^{1}$ Bagian Ilmu Kesehatan Anak, ${ }^{2}$ Bagian Ilmu Bedah Fakultas Kedokteran Universitas Sriwijaya/RSUP Dr. Moh. Hoesin, Palembang
}

Latar belakang. Tidak semua kelainan jantung menimbulkan gejala klinis. Pemeriksaan ekokardiografi tidak semuanya tersedia di fasilitas kesehatan terbatas.

Tujuan. Untuk mendeteksi kelainan jantung pada siswa-siswi sekolah dasar di Palembang melalui pemeriksaan auskultasi jantung dan elektrokardiografi.

Metode. Desain penelitian uji diagnostik dengan pendekatan cross sectional pada siswa-siswa sekolah dasar di kota Palembang. Penelitian dilakukan dari bulan Agustus sampai dengan November 2019. Subyek penelitian sebanyak 280 anak sekolah dasar. Semuanya dilakukan pemeriksaan auskultasi jantung, elektrokardiografi, dan ekokardiografi

Hasil. Subyek 280 anak sekolah dasar, terdiri dari 130 laki-laki dan 150 perempuan. Rerata umur 9,6 tahun (rentang 5-14) tahun. Median berat badan $27 \mathrm{~kg}$. Pada pemeriksaan auskultasi ditemukan 79,2\% normal, 9,2 \% bising sistolik, 2,1 \% bising diatolik, dan $7,1 \%$ bising inosen. Hasil elektrokardiografi, normal $97,1 \%$, sinus takikardi $1,4 \%$, sinus bradikardi $0,4 \%$, hipertrofi ventrikel kiri $0,7 \%$, right bundle branch block $0,4 \%$. Hasil ekokardiografi, penyakit jantung rematik subklinis 20 anak, persisten foramen ovale 1 anak, pulmonal stenosis 2 anak dan hipertensi pulmonal primer 10 anak. Sensitivitas dan spesifisitas auskultasi jantung 90\% dan 91\%. Nilai prediksi positif dan negatif auskultasi jantung 57,69\% dan 98,6\%. Sensitivitas dan spesifisitas elektrokardiografi 6,06\% dan $97,57 \%$. Nilai prediksi positif dan negatif elektrokardiografi $25 \%$ dan $88,6 \%$.

Kesimpulan. Auskultasi jantung cukup akurat untuk deteksi awal kelainan jantung pada anak dibandingkan elektrokardiografi. Sari Pediatri 2020;22(3):164-8

Kata kunci: auskultasi, elektrokardigrafi, ekokardiografi, kelainan jantung

\section{Accuracy of Cardiac Auscultation and Electrocardiography for Detection Cardiac Abnormalities in Children}

Ria Nova, ${ }^{1}$ Deny Salverra Yosy, ${ }^{1}$ Bermansyah ${ }^{2}$

Background. Not all heart abnormalities cause clinical symptoms. Not all echocardiographic examinations are available in limited health facilities.

Objective. To detect heart abnormalities in primary school students in Palembang by performing cardiac auscultation and electrocardiography examination.

Methods. Design of diagnostic test study with a cross sectional approach at primary school students in Palembang. The study was conducted from August to November 2019. The subjects were 280 primary school children. All were examined for cardiac auscultation, electrocardiography, and echocardiography.

Result. The subjects were 280 primary school children, consisting of 130 boys and 150 girls. The average age is 9.6 years (range 5-14) years. Median body weight $27 \mathrm{~kg}$. On auscultation, examination found $79.2 \%$ normal, $9.2 \%$ systolic mu, $2.1 \%$ diastolic noise and $7.1 \%$ plain noise. Electrocardiographic results, normal $97.1 \%$, sinus tachycardia $1.4 \%$, sinus bradycardia $0.4 \%$, left ventricular hypertrophy $0.7 \%$, right branch bundle block $0.4 \%$. Echocardiographic results, 20 subclinical rheumatic heart disease, persistent foramen ovale 1 child, pulmonary stenosis 2 children and primary pulmonary hypertension 10 children. The sensitivity and specificity of cardiac auscultation $90 \%$ and $91 \%$. Positive and negative predictive values for cardiac auscultation are 57.69\% and 98.6\%. Electrocardiographic sensitivity and specificity $6.06 \%$ and $97.57 \%$. Positive and negative predictive value of electrocardiography $25 \%$ and $88.6 \%$.

Conclusion. Cardiac auscultation is more accurate for early detection of cardiac abnormalities in children than electrocardiography. Sari Pediatri 2020;22(3):164-8

Keywords: auscultation, electrocradiography, echocardiography, cardiac abnormalities

Alamat korespondensi: Deny Salverra Yosy. Departemen Ilmu Kesehatan Anak Fakultas Kedokteran Universitas Sriwijaya. Gedung Selincah Lantai 4, Jl. Jend. Sudirman Kilometer 3.5, Palembang 30126. Email : ochie.dr@gmail.com 
$\mathrm{K}$ elainan jantung pada anak dapat disebabkan oleh penyakit jantung bawaan (PJB), demam rematik akut (DRA) atau penyakit jantung (PJR), dan gangguan irama jantung yang tidak terdeteksi waktu lahir dan bayi. Prevalensi PJB cukup tinggi, yaitu 8 sampai 10 dari tiap 1000 kelahiran hidup. ${ }^{1}$ Penyakit jantung rematik juga bisa tidak terdeteksi seperti subklinis PJR. Prevalensi PJR subklinis di negara berkembang cukup tinggi, yaitu sekitar 21 dari 1000 anak. $^{2-5}$ Hal ini berhubungan dengan tingkat kepadatan pendudukan dan kebersihan lingkungan. Sementara prevalensi gangguan irama jantung pada anak lebih kurang 1,5 per 1000 anak.

Tidak semua kelainan jantung pada anak memberikan gejala khas, seperti sesak napas dan gagal tumbuh. Bahkan, sebagian besar tidak menimbulkan gejala. Untuk itu, dilakukan pemeriksaan ekokardiografi. Namun, pemeriksaan ekokardiografi tidak selalu tersedia di semua fasilitas kesehatan. Di samping itu, ekokardiografi memerlukan kompetensi khusus sehingga tidak semua petugas kesehatan dapat melakukannya.

Sebenarnya, melakukan auskultasi dengan cermat dapat membantu untuk mendeteksi kelainan jantung yang disebabkan PJB dan PJR. Menurut penelitian yang dilakukan oleh Kagaya dkk, ${ }^{6}$ ketepatan identifikasi bising jantung mahasiswa kedokteran dan peserta pendidikan dokter spesialis lebih tinggi dibandingkan identifikasi suara jantung normal. Dengan demikian, kelainan jantung yang pada pemeriksaan fisis ditemukan bising jantung lebih mudah terdeteksi melalui auskultasi yang cermat.

Sementara penelitian yang dilakukan oleh $\mathrm{Zhao}^{7}$ menilai akurasi auskultasi bising jantung pada bayi dalam deteksi dini PJB. Begitu juga dengan pemeriksaan elektrokardiografi, pada dasarnya mudah dikerjakan, juga dapat membantu mendeteksi kelainan jantung maupun kelainan irama jantung. Seperti penelitian $\operatorname{Vetter}^{8}$ yang dilakukan di Tokyo Jepang pada anak sekolah dan remaja, EKG merupakan pemeriksaan rutin yang dilakukan sejak tahun 1973. Lebih kurang 2,7\% anak sekolah memerlukan pemeriksaan lebih lanjut setelah dilakukan EKG dan terdiagnosis 0,0024\% mengalami gangguan irama jantung. Pada suatu studi metaanalisis yang dilakukan oleh Rodday dkk ${ }^{9}$ di Boston, dari 6954 studi, terdapat 396 studi yang dianalisis pada anak yang tanpa gejala kelainan jantung, ditemukan 45 kardiomiopati hipertropi, 7 dengan long QT syndrome, dan 136 dengan sindrom Wolff-Parkinson-White (WPW). Sementara itu Wang dkk ${ }^{10}$ di Amerika Serikat melakukan penelitian dengan menggabungkan gambaran EKG dan auskultasi bunyi jantung untuk mendeteksi kelainan jantung, dan mendapatkan hasil yang mirip antara pemeriksaan fisis dan EKG. Namun, bagaimana akurasi dari pemeriksaan auskultasi jantung dan elektrokardiografi ini belum pernah diteliti sebelumnya di Palembang.

Berdasarkan data di atas, peneliti dan tim menilai perlu dilakukan penelitian karena banyak kelainan jantung pada awalnya tidak menunjukkan gejala klinis yang signifikan, seperti pada PJR subklinis dan PJB dengan defek kecil. Skrining kelainan jantung pada anak sekolah dasar dengan pemeriksaan sederhana auskultasi jantung dan elektrokardiografi diharapkan dapat mendeteksi kelainan jantung sejak awal sehingga dapat mencegah komplikasi lanjutan sehingga dapat mengurangi morbiditas dan mortalitas. Di kota Palembang masih banyak lokasi sekolah dasar di daerah padat penduduk yang memungkinkan untuk penularan infeksi Streptokokus sebagai faktor risiko demam rematik akut/PJR. Di samping itu, alasan ekonomi menjadi salah satu faktor karena biaya yang cukup mahal dan jangkauan fasilitas kesehatan yang terbatas untuk pemeriksaan ekokarkardiografi.

\section{Metode}

Desain penelitian yang digunakan adalah uji diagnostik dengan metode potong lintang. Sampel penelitian adalah siswa-siswi sekolah dasar yang berada di wilayah kota Palembang, mulai Agustus-November 2019. Kriteria inklusi adalah siswa-siswi sekolah dasar yang bersekolah di lokasi penelitian dan bersedia ikut penelitian. Kriteria eksklusi adalah siswa-siswi yang telah diagnosis kelainan jantung sebelumnya dan siswa-siswi yang tidak bersedia ikut dalam penelitian. Teknik pengambilan sampel adalah consecutive sampling dengan memasukkan semua subjek penelitian yang memenuhi kriteria inklusi ke dalam sampel. Didapat 280 anak sebagai jumlah sampel. Penelitian ini telah memperoleh kelaikan etik dari Komite Etik Penelitian Kesehatan RSUP. Moh Hoesin dan Fakultas Kedokteran Universitas Sriwijaya, Palembang.

Cara kerja penelitian dimulai dengan melakukan pemeriksaan auskultasi jantung dan elektrokardiografi pada anak yang telah memenuhi kriteria inklusi dan eksklusi. Pemeriksaan auskultasi jantung dan ekokardiografi dilakukan oleh seorang konsultan kardiologi anak. Adapun data yang didapatkan berupa prevalensi PJB, PJR, dan gangguan irama jantung atau tanpa kelainan jantung. 
Data yang diperoleh lalu dimasukkan ke dalam program perangkat lunak SPSS ${ }^{\oplus} 24$. Analisis data berkelanjutan dilakukan dengan uji T. Selanjutnya dilakukan uji sensisitivitas dan spesifisitas untuk menghitung nilai prediksi negatif dan positif. Tingkat kemaknaan dinyatakan bila $\mathrm{p}<0,05$

\section{Hasil}

Subyek penelitian terdiri dari 130 (48,4\%) laki-laki dan $150(53,6 \%)$ perempuan. Usia bervariasi antara 5 sampai 14 tahun. Sebagian besar sekolah dasar yang di-sampling adalah sekolah dasar di daerah padat penduduk. Karakteristik umum subyek penelitian dapat tertera pada Tabel 1.

Dari Tabel 1 tidak didapatkan perbedaan yang bermakna proporsi jenis kelamin subyek penelitian. Median usia adalah 9,6 tahun, dengan rentang usia 5 sampai 14 tahun, karena subyek penelitian adalah anak usia sekolah dasar dari kelas 1 sampai dengan kelas 6 sekolah dasar. Status gizi terbanyak adalah gizi baik 146 $(52,1 \%)$, diikuti dengan gizi kurang/wasted $92(32,9)$. $\mathrm{Hal}$ ini disebabkan sebagian besar subyek penelitian berasal dari tingkat sosial ekonomi menengah ke bawah di lingkungan padat penduduk.

Tabel 1. Karakteristik umum subyek penelitian

\begin{tabular}{lc}
\hline Karakteristik & Frekuensi \\
\hline Jenis kelamin, n (\%) & \\
$\quad$ Laki-laki & $130(46.4)$ \\
$\quad$ Perempuan & $150(53.6)$ \\
Usia, tahun & \\
$\quad$ Rerata, SD (rentang) & $9,6,1,9(5-14)$ \\
Berat badan, kg & \\
$\quad$ Median (rentang) & $27(14-77)$ \\
Status gizi, n (\%) & \\
$\quad$ Gizi baik & $146(52,1)$ \\
Wasted & $92(32,9)$ \\
Over weight & $30(10,7)$ \\
Obes & $12(4,3)$ \\
Kepadatan hunian rumah, n (\%) & \\
$\quad<3$ & $68(24,3)$ \\
4-6 & $191(68,2)$ \\
$>6$ & $21(7,5)$ \\
Penghasilan keluarga/bulan, n, rupiah & \\
1.000.000-3.000.000 & $219(78,2)$ \\
$3.000 .000-5.000 .000$ & $58(20,7)$ \\
$>5.000 .000$ & $3(1,1)$ \\
\hline
\end{tabular}

Kisaran penghasilan keluarga per bulan, masih di bawah rata-rata, sebesar 1.000.000-3.000.000 (78,2\%). Kepadatan hunian subyek penelitian tertera pada Tabel 1, dengan jumlah penghuni tiap rumah terbanyak 4-6 orang, terdapat pada 191 (68,2\%) subyek. Gambaran auskultasi jantung dan elektrokardiografi tertera pada Tabel 2.

Tabel 2. Gambaran auskultasi jantung dan elektrokardiografi

\begin{tabular}{lc}
\hline Karakteristik & Frekuensi \\
\hline Gambaran auskultasi jantung, n (\%) & \\
Normal & $228(81,4)$ \\
Bising sistolik & $26(9,3)$ \\
Bising diastolik & $4(1,4)$ \\
Bising innocent & $22(7,9)$ \\
& \\
Gambaran elektrokardiografi, n (\%) & \\
Normal & $272(97,1)$ \\
Sinus takikardia & $4(1,4)$ \\
Sinus bradikardi & $1(0,4)$ \\
Hipertrofi ventrikel kiri & $2(0,7)$ \\
Right bundle branch block & $1(0,4)$ \\
\hline
\end{tabular}

Gambaran kelainan jantung subyek penelitian dari pemeriksaan ekokardiografi tertera pada Tabel 3. Sensitivitas auskultasi untuk mendeteksi kelainan jantung 90\%, spesifisitas $91 \%$, nilai prediksi positif $57,69 \%$ dan nilai prediksi negatif $98,6 \%$. Sensitivitas elektrokardiografi untuk mendeteksi kelainan jantung $6,06 \%$, spesifisitas $97,5 \%$, nilai prediksi positif $25 \%$, dan nilai prediksi negatif $88,6 \%$

Pemeriksaan elektrokardiografi mempunyai sensitivitas rendah untuk deteksi kelainan jantung $(6,06 \%)$ karena banyak kelainan jantung yang tidak menunjukkan abnormalitas pada pemeriksaan elektrokardiografi, terutama kelainan jantung ringan yang belum terjadi pembesaran ruang-ruang jantung. Sebaliknya, abnormalitas elektrokardiografi bisa terdapat pada anak normal. Hal ini disebabkan karena faktor stres atau ketakutan anak waktu dilakukan pemeriksaan sehingga memengaruhi hasil elektrokardiografi, terutama peningkatan denyut jantung. Selain itu ditemukan right bundle branch block (RBBB) pada elektrokardiografi hanya pada satu lead pada kertas elektrokardiografi tanpa didukung oleh gejala klinis merupakan variasi normal yang tidak perlu dilakukan intervensi. Walaupun demikian, skrining awal pemeriksaan elektrokardiografi tetap harus dikonfirmasi dengan pemeriksaan baku emas deteksi kelainan jantung yaitu ekokardiografi. 
Tabel 3. Gambaran kelainan jantung dari pemeriksaan ekokardiografi

\begin{tabular}{lc}
\hline Karakteristik & Frekuensi \\
\hline Ekokardiografi, $\mathrm{n}(\%)$ & $247(88,2)$ \\
$\quad$ Normal & $20(7,1)$ \\
Penyakit jantung rematik subklinis & $1(0,4)$ \\
Persistent foramen ovale & $2(0,7)$ \\
Pulmonal stenosis & $10(3,6)$ \\
Hipertensi pulmonal primer & \\
Gambaran keterlibatan katup PJR subklinis, $\mathrm{n}$ & 2 \\
Mitral regurgitasi & 3 \\
Aorta regurgitasi & 8 \\
Mitral dan aorta regurgitasi & 5 \\
Milral, aorta dan tricuspid regurgitasi & 2 \\
Mitral, aorta, tricuspid dan pulmonal & \\
regurgitasi & \\
Gambaran Doppler regurgitasi katup & \\
Length regurgitasi katup mitral, $\mathrm{n}(\%)$ & \\
$\leq 2 \mathrm{~cm}$ & 10 \\
$>2 \mathrm{~cm}$ & 7 \\
Velocity regurgitasi katup mitral, $\mathrm{n}(\%)$ & \\
$\leq 3 \mathrm{~m} / \mathrm{s}$ & 9 \\
$>3 \mathrm{~m} / \mathrm{s}$ & 8 \\
Length regurgitasi katup aorta, $\mathrm{n}(\%)$ & \\
$<2 \mathrm{~cm}$ & 12 \\
$>2 \mathrm{~cm}$ & 6 \\
Velocity regurgitasi katup aorta, $\mathrm{n}(\%)$ & \\
$<3 \mathrm{~m} / \mathrm{s}$ & \\
$>3 \mathrm{~m} / \mathrm{s}$ & \\
Gambaran hipertensi pulmonal primer, $\mathrm{n}$ & \\
Trikuspid regurgitasi & \\
Pulmonal regurgitasi & \\
Trikuspid dan pulmonal regurgitasi & 3 \\
\hline & \\
\hline
\end{tabular}

Tabel 4. Uji diagnostik auskultasi dalam mendeteksi kelainan jantung

\begin{tabular}{lccc}
\hline \multirow{2}{*}{ Karakteristik } & \multicolumn{2}{c}{ Kelainan jantung } & \multirow{2}{*}{ Total } \\
\cline { 2 - 3 } & Ada & Tidak ada & \\
\hline Ada bising/murmur & 30 & 22 & 52 \\
Tidak ada murmur & 3 & 225 & 228 \\
\hline Total & 33 & 247 & 280 \\
\hline
\end{tabular}

Tabel 5. Uji diagnostik pemeriksaan elektrokardiografi dalam mendeteksi kelainan jantung

\begin{tabular}{lccc}
\hline \multirow{2}{*}{ Karakteristik } & \multicolumn{2}{c}{ Kelainan jantung } & \multirow{2}{*}{ Total } \\
\cline { 2 - 3 } & Ada & Tidak ada & \\
\hline EKG abnormal & 2 & 6 & 8 \\
EKG normal & 31 & 241 & 272 \\
\hline Total & 33 & 247 & 280 \\
\hline
\end{tabular}

\section{Pembahasan}

Dari data karakteristik umum didapatkan jenis kelamin laki-laki $46,4 \%$ dan perempuan $53,6 \%$. Usia bervariasi antara umur 5 sampai 14 tahun. Sebagian besar sekolah dasar yang di-sampling adalah sekolah dasar di daerah padat penduduk. Status gizi terbanyak adalah gizi baik $52,1 \%$ dan wasted 32,9\%. Sosial ekonomi subyek penelitian adalah menengah ke bawah. Pemeriksaan auskultasi paling banyak didapatkan hasil normal $79,2 \%$, bising sistolik $9,2 \%$, bising diastolik $2,1 \%$ dan bising innocent 7,1\%. Temuan bising innocent pada studi ini lebih rendah dari studi yang dilakukan oleh Oort $\mathrm{dkk}^{11}$ pada usia 5-14 tahun (13\%). Sebagian besar hasil elektrokardiografi adalah normal, diikuti oleh sinus takikardi, sinus bradikardi, LVH dan RBBB.

Hasil ekokardiografi normal adalah $88,2 \%$, PJR subklinis $7,1 \%$, persistent foramen ovale $0,4 \%$, pulmonal stenosis $0,7 \%$ dan hipertensi pulmonal primer 3,6\%. Prevalensi PJR subklinis penelitian kami lebih tinggi dari pada penelitian yang dilakukan oleh Shresta $\mathrm{dkk}^{12}$ yang melaporkan skrining PJR subklinis anak usia sekolah sebesar 2,1\%. Keterlibatan katup pada PJR subklinis yang terbanyak adalah katup mitral adan aorta. Gambaran ekokardiografi hipertensi pulmonal sebanyak 10 anak. Hipertensi pulmonal primer sering terjadi pada anak yang sering menderita infeksi saluran napas akut

Akurasi auskultasi dalam mendeteksi kelainan jantung penelitian kami digambarkan dengan nilai sensitivitas $90 \%$ dan spesifisitas $91 \%$. Hampir sama dengan penelitian yang dilakukan oleh Zhao $\mathrm{dkk}^{7} \mathrm{di}$ China. Zhao dkk melaporkan sensitivitas bising jantung derajat 3 ke atas untuk deteksi PJB 83,3\% (70,42-91,30) dengan spesifisitas 99,88 (99,76-99,94). Nilai prediksi positif auskultasi penelitian kami adalah $57,69 \%$ dan nilai prediksi negatif auskultasi adalah 98,6\%.

Pada penelitian Zhao $\mathrm{dkk}^{7}$ juga didapatkan nilai prediksi positif $65,57(53,05-76,25)$ dan nilai prediksi negatif 98,88 (99,76-99,94). Perbedaan dengan penelitian kami adalah penelitian Zhao dilakukan di ruang perawatan perinatologi. Hasil ini juga hampir sama dengan penelitian yang dilakukan oleh Ageliki $\mathrm{dkk}^{13}$ di Athena, Yunani, yang melaporkan sensitivitas auskultasi jantung $80,5 \%$ dan spesifisitas 90 , ditemukan bising innocent pada 20 orang anak tanpa disertai dengan kelainan jantung. Berdasarkan penelitian yang dilakukan oleh Van Oort dkk ${ }^{11}$ di Leiden, Belanda, dilaporkan bising innocent sebagian (9\%) pemeriksaan dilakukan oleh konsultan jantung anak. 
Nilai prediksi positif dan negatif sebagian besar terjadi pada anak normal, terutama pada anak sekolah dasar umur 5 sampai 14 tahun. Temuan bising innocent berbeda-beda berdasarkan kelompok umur. Pada kelompok umur 5-14 tahun ditemukan bising innocent sebesar $13 \% .^{11}$

Akurasi elektrokardiografi dalam mendeteksi kelainan jantung digambarkan dengan nilai sensitivitas $97,57 \%$ dan spesifisitas $25 \%$. Nilai prediksi positif auskultasi adalah $25 \%$ dan nilai prediksi negatif auskultasi adalah $88,6 \%$. Hal ini disebabkan pada kelainan jantung ringan belum terjadi pembesaran ruang-ruang jantung sehingga tidak menunjukkan kelainan pada elektrokardiografi.

\section{Kesimpulan}

Dapat disimpulkan bahwa pemeriksaan auskultasi yang cermat cukup akurat dalam deteksi awal kelainan jantung dengan nilai sensitivitas dan spesifisitas cukup tinggi. Sementara akurasi pemeriksaan elektrokardiografi dalam deteksi kelainan jantung sangat rendah. Demikian pula dengan sensitivitas yang juga sangat rendah, tetapi spesifisitas dalam mendeteksi kelainan jantung cukup tinggi. Diperlukan penelitian lanjutan dengan jumlah sampel yang lebih besar. Disarankan, pada anak sekolah dasar di Palembang untuk melakukan skrining kelainan jantung melalui pemeriksaan auskultasi jantung dan elektrokardiografi secara rutin.

\section{Daftar pustaka}

1. Park MK. Acute rheumatic fever. Dalam: Park MK, penyunting. Pediatric cardiology for practitioners. Edisi kelima. Philadelphia: Mosby Elsevier; 2008.h.469-78.

2. Baroux N, Rouchon B, Huon B, Germain A, Meunier JM, D'Ortenzio E. High prevalence of rheumatic heart disease in school children detected by echocardiography screening in New Caledonia. J Paediatr Child Health 2013;49:109-14.
3. WHO Study Group. Rheumatic fever and rheumatic heart disease. WHO Technical Report Series, No 923. Geneva: World Health Organization; 2004.

4. Siregar AA. Demam Rematik dan penyakit jantung rematik permasalahan Indonesia. Pidato Pengukuhan Jabatan Guru Besar Tetap pada Fakultas Kedokteran. Universitas Sumatera Utara. 2007. Naskah tidak dipublikasi.

5. Watkins DA, Johnson CO, Colquhoun SM, Karthikeyan G, Beaton Andrea, Bukhman Gene, dkk. Global, regional, and national burden of rheumatic heart disease 1990-2015. N Engl J Med 2017;377:713-22.

6. Kagaya Y, Tabata M, Arata Y, Kameoka J, Ishii S. Variation in effectiveness of a cardiac auscultation training class with a cardiology patient simulator among heart sounds and murmurs. J Cardiol 2017;70:192-8.

7. Zhao Q, Niu C, Liu F, Wu L, Xiao-jing M, Guo-ying H. Accuracy of cardiac auscultation in detection of neonatal congenital heart disease by general paediatricians. Cardiology in the Young 2019;29:679-83.

8. Vetter VL. Electrocardiographic screening of all infants, children, and teenagers should be performed. Circulation 2014;130:688-97.

9. Rodday AM, Triedman JK, Alexander ME, Cohen JT, Ip S, Newburger JW, Parsons SK, Trikalinos TA, Wong JB, Leslie LK. Electrocardiogram screening for disorders that cause sudden cardiac death in asymptomatic children: a metaanalysis. Pediatrics 2012 ;129:e999-1010.

10. Wang F, Mahmood TS, Beymer D. finding disease similarity by combining ECG with heart auscultation sound. Computers in Cardiol 2007;34:261-4.

11. Van Oort A, Le Blanc-Botden M, De Boo T, Van Der WerfT, Rohmer J, Daniels O. The vibratory innocent heart murmur in schoolchildren: difference in auscultatory findings between school medical officers and a pediatric cardiologist. Pediatric Cardiol 1994;15:282-7.

12. Shrestha NR. Karki P, Mahto R, Gurung K, Pandey N, Agrawal $\mathrm{K}$, dkk. Prevalence of subclinical rheumatic heart disease in Eastern Nepal: a schoolbased cross-sectional study. JAMA Cardiol 2016;1:89-96.

13. Ageliki KA, Sotirios F, Sotirios T, Alexandra M, Gabriel D, Stefanos M. Pediatr Cardiol 2011;32:473-7. 